\title{
Patient Satisfaction in Croatian Nationwide Mammography Screening Program
}

\author{
Brnić Zoran, Kašnik Kristina, Kašnik Katarina, Brnić Vedran, Borojević Nikola, \\ Ljubešić Luka*, Schmidt Saša, Krpan Tomislav \\ Clinical Hospital Center "Sisters of Mercy", Zagreb, Croatia \\ Email: *lukaljubesic@yahoo.com
}

How to cite this paper: Zoran, B., Kristina, K., Katarina, K., Vedran, B., Nikola, B., Luka, L., Saša, S. and Tomislav, K. (2017) Patient Satisfaction in Croatian Nationwide Mammography Screening Program. International Journal of Clinical Medicine, 8, 159-166.

https://doi.org/10.4236/ijcm.2017.83016

Received: January 23, 2017

Accepted: March 28, 2017

Published: March 31, 2017

Copyright $\odot 2017$ by authors and Scientific Research Publishing Inc. This work is licensed under the Creative Commons Attribution International License (CC BY 4.0).

http://creativecommons.org/licenses/by/4.0/

\begin{abstract}
Mammographic screening programs are essential in timely detection and effective treatment of breast cancer. Since 2006, Croatia implemented a national MSP which asks for a regular biannual mammography for all women 50 - 69 years of age. First-visit screening attendance in the country is estimated at $58.3 \%$ with the trend of gradually decreasing re-attendance rates. Since patient satisfaction with the screening procedure may influence subsequent adherence, this study aimed to assess patient satisfaction in order to predict and improve patient re-attendance rate, a first-time effort of such kind in Croatia. 201 random patients undergoing mammography screening procedure at four facilities in Croatia were asked to complete an anonymous questionnaire which specifically evaluated the following aspects of patient experience: patient attitude, facility surroundings, staff attitude and pre-examination information transfer, associated physical pain, psychological discomfort, and finally overall patient impressions and satisfaction. The majority of our examinees expressed high satisfaction with MSP and an intention to re-screen; patient attitude, facility environment and staff attitude were deemed overly positive, whereas the majority of patients estimated the physical and psychological pain associated tolerable. These results suggest that patient satisfaction is not a critical factor influencing future adherence rate in MSP, and other components of the program should be evaluated and improved.
\end{abstract}

\section{Keywords}

Croatian, Mammography, Screening Program, Patient Satisfaction

\section{Introduction}

Mammography (MG) plays a central role in the diagnosis of breast cancer (BC), the 2 nd leading cause of cancer-related death in women. Mammographic screening 
programs (MSP) are of essential importance in timely detection and effective treatment of BC [1] [2]. National MSP is a significant logistical, organizational and financial challenge, whose success depends highly on attendance rate. Since 2006 Croatian national MSP calls for a regular biannual mammography for all women 50 - 69 years of age. First-visit screening attendance in Croatia is estimated at $58.5 \%$ [3]. Subsequent women's re-attendance may be influenced by the experience and satisfaction with their previous examination [4] [5]. In order to predict and improve re-attendance rate many studies have demonstrated the importance of evaluating patient satisfaction [6] [7] [8] [9] [10]. Patient satisfaction may be assessed in terms of specific contributing factors such as ease of accessibility, facility and staff resources, pre-examination information transfer, and physical and psychological discomfort induced by the examination. A successful mammography examination should involve timely scheduling, clear pre-examination information on the benefits and precautions of the procedure, comfortable waiting and examination rooms, welcoming professional staff and an agreeable breast compression technique during the examination. Considering that high patient satisfaction with the procedure could improve patient adherence rate, which has been decreasing in recent years, we designed this study to assess patient experience in a sample of women participating in Croatian national MSP. A first-time effort of such kind in quality assurance/quality control activities, which have not been sufficiently and systematically implemented in Croatia, this assessment contributes to identifying possible organizational and logistic weaknesses and opportunities for improvement of the program.

\section{Materials and Methods}

The series consists of a sample of 201 women undergoing regular MSP in the period from January to May 2014, aged 50 - 69 (average 58) years. Ten women per day undergoing screening MG procedure were randomly chosen to be surveyed at 4 university hospitals, 1 county hospital and 1 secondary healthcare facility (Dom zdravlja) using an anonymous questionnaire completed immediately after the examination with the authors' assistance. Informed consent was obtained from the patients and approved by the ethics committee of the MSP. The questionnaire consisted of 40 questions covering the following specific categories: general patient profile, level of information before MG, ease of accessibility and comfortableness of the mammography facility, staff attitude towards the patient, patient impressions of the mammographer, physical discomfort and pain of the examination, associated psychological discomfort, post-examination impressions and general patient satisfaction with MG. Questions assessing patient attitudes utilized Likert's Scale of 5 possible answers (1-strongly agree, 2-partially agree, 3-neither agree nor disagree, 4-mostly disagree, 5-strongly disagree). Pain level was assessed by the Visual Analogue Scale (VAS) $(0=$ no pain, $10=$ severe pain) [11]. The reliability of the questionnaire was first assessed by a pilot study of 20 women, after which the questions were revised and improved. The descriptive study design was estimated as having good reliability by a Cronbach's $a$ 
coefficient $>0.7$.

\section{Results and Discussion}

Success of national MSP depends highly on patient adherence rate, which is closely associated with the experiences related to the screening procedure. Assessment of general and specific factors influencing patient experience helps recognize potential areas for improving patient satisfaction and future adherence. Specifically, this study evaluated patient attitude, facility surroundings, staff attitude and pre-examination information transfer, associated physical pain, psychological discomfort, and finally overall patient impressions and satisfaction.

Positive patient attitude before the examination contributes to later patient satisfaction with the process [12]. In our study, a great majority of patients $(97.0 \%$, 195) stated that they agree that MG is reliable in detection of $\mathrm{BC}$, and have a positive attitude about the procedure, which may be the consequence of educational advertisement campaigns undertaken in recent years in the public media, and educational written materials received with the letter of invitation for mammography screening. The authors of the study had an opportunity to observe women sitting and chattering in waiting-rooms prior to official survey and observed spontaneous affirmative conversations among participants with little or no doubts about the accuracy of $\mathrm{MG}$ and radiation risks related.

The environment of the mammographic screening facility is a contributing factor in decreasing patient anxiety. Great majority $(93.5 \%, 188)$ of our examinees found the environment of the waiting rooms pleasant, 57.2\% (115) agrees that the examination room is pleasant, but $30.3 \%$ (61) of patients completely disagree about adequacy of privacy during the procedure. Pleasant and welcoming environment of the waiting and examination room positively affects patient satisfaction [13], and could be achieved even with minor modifications if the staff is aware of this issue. In some institutions surveyed in our study there were no separated cabins for undressing available, and women usually prepared for the examination within the examination room in the presence of the mammographer preparing MG equipment for the exposure. Such limited privacy may be unpleasant for the women undergoing screening. Although MG units are rarely located in underground floors of old hospital buildings with elevators reserved only for staff, and limited parking areas for customers, 65.6\% (132) of examinees did not have difficulties arriving to the place of the examination, considering traffic accessibility, parking opportunities and infrastructural barriers. An important factor that limits attendance rate to MSP in sparsely populated rural areas of Croatia is the lack of regular public transportation (e.g. Lika region, small islands) which discourages women to attend, although engagement of mobile MG units visiting these areas partially solves the problem.

Positive staff attitude and pre-examination information transfer are important contributing factors to patient satisfaction. Negative experience regarding staff attitude has been shown to decrease overall patient satisfaction with the proce- 
dure [14]. Insufficient knowledge and distrust about the examination have been associated with dissatisfaction [12]. Pleasant and knowledgeable staff [15], as well as extra time and patience spent in explaining the procedure could decrease anxiety and improve rescreening rate [16]. Verbal information preceding the examination decreases patient anxiety, particularly in first time participants [17]. $87.5 \%$ (176) of our participants are satisfied with the manner of reception immediately after the entry to the MG facility, believe they "had been given clear and adequate information regarding the benefits and cautions of the procedure", that "the examination had not been performed in a hurry", and that "the personnel did their best to make them feel comfortable". However, only 67.2\% (135) states they have been explained that breast pain and tenderness may appear following the procedure which would not be a reason for concern. Moreover, a significant number of women $(17.9 \%, 36)$ think that the staff failed to give a proper explanation about the pain during breast compression, which was expected from them.

Subjective patient assessment of mammographer's professional skills could have an impact on patient satisfaction, considering that the women have been invited to the procedure and expect a high service quality and professional courtesy. More than a half $(51.3 \%, 103)$ of the patients had an impression that the person who performed the examination was insufficiently trained and professionally skilled for such a task. Some studies [12] have shown that such a perception is due to the inability of non-professionals to properly estimate professional skills of the staff. The objective reasons may include limited training of some mammographers, especially younger ones which participate in MSP for financial reasons outside of regular working hours, often fatigued after morning clinical duties; also overbooking of patients, usually done due to variable attendance can cause an unexpectedly high workload and the mammographers to be in a hurry. This finding requires more research, and efforts in additional education and licensing of mammographers participating in MSP is needed. In spite of the abovementioned women's subjective impressions, $89.6 \%$ (180) of them believe that MG has been technically adequately performed and accurate enough for BC detection.

Physical breast pain and discomfort during MG is a significant factor that may cause anxiety and dissatisfaction with the procedure, and various strategies for pain relief could be attempted. 60\% (120) of our patients found the procedure mildly painful or even completely painless (scores 1 - 3 on a 10-point Visual Analog Scale (VAS)), a highly satisfactory result considering the age of participants, and limited technical skills of mammographers in some facilities. The usual breast compression force of $12 \mathrm{daN}$ was comfortable for $46.3 \%$ (93) of the patients, whereas others would ask to decrease the compression force. Great majority of patients $(88.5 \%, 178)$ claim that they completely understand the reasons why breast compression is required to achieve proper quality of images and to reduce breast radiation dose, whereas $(19.4 \%, 39)$ of patients think that MG is an inherently painful examination; $8 \%$ (16) of patients consider the reason being 
was the too small size of their breasts, and 7.5\% (15) the too large size of their breasts.

In one study [18] applying 4\% lidocaine gel prior to compression significantly reduced patient discomfort. The majority $(80.1 \%, 161)$ of women in our study, however, considered administering some kind of pain relief before the examination (e.g. an anesthetic gel) completely unnecessary. Other studies proposed different strategies for reducing pain, including employing music for relaxation [19] or using breast cushions [20]. Breast support plate was experienced as too cold for $22.9 \%$ (46) of patients in our study.

Psychological impressions associated to MG procedure are related to the imaging technique itself (getting undressed, compression) and to the mammographer's social skills and communication ability, and significantly influences patient satisfaction. Majority of women in our series $(87.6 \%, 176)$ have not experienced the procedure psychologically embarrassing or unpleasant, $74.6 \%$ (150) of women agrees that the personnel acted supportively and reassuring, and $85.1 \%$ (171) states that the staff approach was encouraging them for future rescreening. The possibility of recall for further testing after basic MG screening has been confirmed to increase patient anxiety [21] [22], but $80.6 \%$ (162) of our patients agree that they feel no anxiety waiting for their examination results and possible recall.

Overall satisfaction with the MSP was good in the vast majority of examinees ("completely satisfied" $65.6 \%$ (132), "satisfied" $26.9 \%$ (54)), and $87.6 \%$ (176) of them found the associated discomfort negligible compared to possible benefits of MG. Only 6.9\% (14) of women found the overall experience more taxing than they expected. The most $(93.1 \%, 187)$ of women claim their examination experience encourages them to re-screen, and would recommend other women to participate in MSP.

There are some limitations of the study concerning sample patient characteristics, influence of social desirability bias and non-assessment of some factors. Most of the patients have previously undergone MG has found them tolerable: $7.5 \%$ (15) underwent $\mathrm{MG}$ for the first time, 7.9\% (16) previously underwent screening MG once, $17.4 \%$ (35) twice, and 64.2\% (129) three or more times. A more appropriate assessment of screening experience would involve a greater number of first-time participants. The survey was completed in the examination facility, which could have the results affected by social desirability bias [23]. Most participants in the sample were urban-dwelling $(81.6 \%, 111)$, were better educated $(53.2 \%$ (107) were high-school educated and $14.4 \%(29)$ had only primary school), and had greater accessibility to MSP than residents of isolated rural communities. Some factors which could influence patient satisfaction, such as result reporting [24] and information environment [25] have not been assessed. Finally, this study did not account for the discrepancy between the intentions to re-screen and realized re-screening, an already documented phenomenon [14]. All these factors could overestimate the portion of satisfied participants and future patient adherence rate. 


\section{Conclusion}

In conclusion, in this first quality assurance survey in Croatian MSP the majority of our examinees expressed high satisfaction with MSP and an intention to re-screen. More specifically, patient attitude, facility environment and staff attitude were deemed overly positive, whereas the majority of patients estimated the physical and psychological pain associated tolerable. The results of this study suggest that patient satisfaction would not be a critical factor influencing future adherence rate in MSP, and other components of the program should be improved to maintain satisfactory participation.

\section{Ethical Approval}

All procedures performed in studies involving human participants were in accordance with the ethical standards of the institutional and national research committee and with the 1964 Helsinki declaration and its later amendments or comparable ethical standards.

\section{Informed Consent}

Informed consent was obtained from all individual participants included in the study.

\section{References}

[1] Sickles, E.A. (1991) Periodic Mammographic Follow-Up of Probably Benign Lesions: Results in 3184 Consecutive Cases. Radiology, 179, 463-468.

https://doi.org/10.1148/radiology.179.2.2014293

[2] Tabar, L., Fagerberg, C.J., Gad, A., Baldetrop, L., Holmberg, L.H., Grontoft, O., et al. (1985) Reduction in Mortality from Breast Cancer after Mass Screening with Mammography. Randomized Trial from the Breast Cancer Screening Working Group of the Swedish National Board of Health and Welfare. Lancet, 1, 829-832. https://doi.org/10.1016/S0140-6736(85)92204-4

[3] Strnad, M. and Sogoric, S. (2010) National Program of Early Detection of Cancer in Croatia. Acta Medica Croatica, 64, 461-468.

[4] Vaile, M.S.B., Calnan, M., Rutter, D.R. and Wall, R. (1993) Breast Cancer Screening Services in Three Areas: Uptake and Satisfaction. Journal of Public Health Medicine, 15, 37-45. https://doi.org/10.1093/oxfordjournals.pubmed.a042818

[5] Elkind, A. and Eardley, A. (1990) Consumer Satisfaction with Breast Screening: A Pilot Study. Journal of Public Health Medicine, 12, 15-18. https://doi.org/10.1093/oxfordjournals.pubmed.a042498

[6] Nielsen, B., Miaskowski, C., McCoy, C. and Rudisch, M. (1991) The Development and Implementation of Standards of Care in a Breast Cancer Screening Program. Oncology Nursing Forum, 18, 67-72.

[7] Cockburn, J., Hill, D., Irwig, L., De Luise, T., Turnbull, D. and Schofield, P. (1991) Development and Validation of an Instrument to Measure Satisfaction of Participants at Breast Screening Programmes. European Journal of Cancer, 27, 827-831.

[8] Rutter, D.R., Calnan, M., Vaile, M.S.B., Field, S. and Wade, K.A. (1992) Discomfort and Pain during Mammography: Description, Prediction, and Prevention. British Medical Journal, 305, 443-445. https://doi.org/10.1136/bmj.305.6851.443 
[9] Baines, C.J., To, T. and Wall, C. (1990) Women's Attitudes to Screening after Participation in the National Breast Screening Study. A Questionnaire Survey. Cancer, 65, 1663-1669.

https://doi.org/10.1002/1097-0142(19900401)65:7<1663::AID-CNCR2820650735>3. $\underline{0 . \mathrm{CO} ; 2-\mathrm{A}}$

[10] Fallowfield, L.J., Rodway, A. and Baum, M. (1990) What Are the Psychological Factors Influencing Attendance, Non-Attendance, and Re-Attendance at a Breast Screening Centre? Journal of the Royal Society of Medicine, 83, 547-551.

[11] Scott, J. and Huskisson, E. (1976) Graphic Representation of Pain. Pain, 2, 175-184.

[12] Loken, K., Steine, S. and Laerum, E. (1998) Mammography: Influence of Departmental Practice and Women's Characteristics on Patient Satisfaction: Comparison of Six Departments in Norway. Quality in Health Care, 7, 136-141.

https://doi.org/10.1136/qshc.7.3.136

[13] Doyle, C.A. and Stanton, M.T. (2002) Significant Factors in Patient Satisfaction Ratings of Screening Mammography. Radiography, 8, 159-172.

https://doi.org/10.1053/radi.2002.0379

[14] Almog, R., Hagoel, L., Tamir, A., Barnett, O. and Rennert, G. (2008) Quality Control in a National Program for the Early Detection of Breast Cancer: Women's Satisfaction with the Mammography Process. Women's Health Issues, 18, 110-117.

[15] Dullum, J.R., Lewis, E.C. and Mayer, J.A. (2000) Rates and Correlates of Discomfort Associated with Mammography. Radiology, 214, 547-552.

https://doi.org/10.1148/radiology.214.2.r00fe23547

[16] Fine, M.K., Rimer, B.K. and Watts, P. (1993) Women's Responses to the Mammography Experience. The Journal of the American Board of Family Practice, 6, 546555.

[17] Shrestha, S. and Poulos, A. (2001) The Effect of Verbal Information on the Experience of Discomfort in Mammography. Radiography, 7, 271-277. https://doi.org/10.1053/radi.2001.0344

[18] Lambertz, C.K., Johnson, C.J., Montgomery, P.G. and Maxwell, J.R. (2008) Premedication to Reduce Discomfort during Screening Mammography. Radiology, 248, 765-772. https://doi.org/10.1148/radiol.2482071490

[19] Domar, A.D., Eyvazzadeh, A., Allen, S., Roman, K., Wolf, R., Orav, J., et al. (2005) Relaxation Techniques for Reducing Pain and Anxiety during Screening Mammography. American Journal of Roentgenology, 184, 445-447. https://doi.org/10.2214/ajr.184.2.01840445

[20] Dibble, S.L., Israel, J., Nussey, B., Sayre, J.W., Brenner, R.J. and Sickles, E.A. (2005) Mammography with Breast Cushions. Women's Health Issues, 15, 55-63.

[21] Watson, E.K., Henderson, B.J., Brett, J., Bankhead, C. and Austoker, J. (2005) The Psychological Impact of Mammographic Screening on Women with a Family History of Breast Cancer-A Systematic Review. Psychooncology, 14, 939-948. https://doi.org/10.1002/pon.903

[22] Brett, J., Austoker, J. and Ong, G. (1998) Do Women Who Undergo Further Investigation for Breast Screening Suffer Adverse Psychological Consequences? A Multi-Centre Follow-Up Study Comparing Different Breast Screening Result Groups Five Months after Their Last Breast Screening Appointment. Journal of Public Health Medicine, 20, 396-403.

https://doi.org/10.1093/oxfordjournals.pubmed.a024793

[23] Ware, J.E., Davies-Avery, A. and Stewart, A.L. (1978) The Measurement and Meaning of Patient Satisfaction. Health \& Medical Care Services Review, 1, 3-15. 
[24] Dolan, N.C., Feinglass, J., Priyanath, A., Haviley, C., Sorensen, A.V. and Venta, L.A. (2001) Measuring Satisfaction with Mammography Results Reporting. Journal of General Internal Medicine, 16, 157-162.

https://doi.org/10.1093/oxfordjournals.pubmed.a024793

[25] Pearlman, D.N., Rakowski, W., Clark, M.A., Ehrich, B., Rimer, B.K., Goldstein, M.G., et al. (1997) Why Do Women's Attitudes toward Mammography Change over Time? Implications for Physician-Patient Communication. Cancer Epidemiology. Biomarkers and Prevention, 6, 451-457.

Submit or recommend next manuscript to SCIRP and we will provide best service for you:

Accepting pre-submission inquiries through Email, Facebook, LinkedIn, Twitter, etc. A wide selection of journals (inclusive of 9 subjects, more than 200 journals)

Providing 24-hour high-quality service

User-friendly online submission system

Fair and swift peer-review system

Efficient typesetting and proofreading procedure

Display of the result of downloads and visits, as well as the number of cited articles Maximum dissemination of your research work

Submit your manuscript at: http://papersubmission.scirp.org/

Or contactijcm@scirp.org 